\title{
Demand-Driven Acquisitions for Print Books: How Holds Can Help as Much As Interlibrary Loan
}

Gerrit van Dyk

Brigham Young University - Provo, gerrit_vandyk@byu.edu

Follow this and additional works at: https://scholarsarchive.byu.edu/facpub

Part of the Collection Development and Management Commons

\section{Original Publication Citation}

Van Dyk, Gerrit. (2014) Demand-Driven Acquisitions for Print Books: How Holds Can Help as Much as Much As Interlibrary Loan. Journal of Access Service, 11:298-308, 2014. DOI: 10.1080/ 15367967.2014.945120

\section{BYU ScholarsArchive Citation}

van Dyk, Gerrit, "Demand-Driven Acquisitions for Print Books: How Holds Can Help as Much As Interlibrary Loan" (2014). Faculty Publications. 1342.

https://scholarsarchive.byu.edu/facpub/1342

This Peer-Reviewed Article is brought to you for free and open access by BYU ScholarsArchive. It has been accepted for inclusion in Faculty Publications by an authorized administrator of BYU ScholarsArchive. For more information, please contact ellen_amatangelo@byu.edu. 


\title{
Demand-Driven Acquisitions for Print Books: How Holds Can Help as Much As Interlibrary Loan
}

\author{
GERRIT VAN DYK \\ Harold B. Lee Library, Brigham Young University, Provo, UT
}

\begin{abstract}
While there is a growing field of literature surrounding demanddriven acquisitions (DDA) for electronic books, libraries have been relatively silent regarding DDA for print books, with the notable exception of using interlibrary loan (ILL). This study will discuss how libraries can examine holds queue demand in conjunction with ILL to make collection development decisions related to print materials. It will also discuss how to work with catalogers to deflect ILL requests for these same high-demand items, so they can stay in the library for local patrons.
\end{abstract}

KEYWORDS Circulation, interlibrary loan, access services

\section{INTRODUCTION}

Over the past decade libraries have increasingly discussed the value of using interlibrary loan (ILL) as a collection development tool for both monographs and serials. When a book is requested, libraries have reviewed it for purchase rather than to borrow based on a wide variety of criteria, depending on local policies. Similarly, when articles are borrowed from the same journal, that journal is reviewed for subscription. As journal subscriptions have gradually migrated from a primarily print environment to an increasingly electronic environment, ILL has continued to be an important tool in making these collections decisions. However, since e-books are more complicated to purchase (and even more complicated to lend), ILL has not been as influential in assisting with e-book demand-driven acquisitions (DDA) decisions. Rather, ILL usually is only included in print monograph DDA discussions.

(c) Gerrit van Dyk

Address correspondence to Gerrit van Dyk, Harold B. Lee Library, Brigham Young University, 2247 HBLL, Provo, UT 84602. E-mail: gerrit_vandyk@byu.edu 
The purpose of this study is not to change this mentality but to suggest that holds can also play a role in print DDA dialogue. As e-books stabilize, ILL and holds will eventually become as important to e-book DDA as they have been for print monographs. For now, this article will demonstrate a workable model in which these two traditionally separate and siloed services can combine to create a more powerful collections development tool.

\section{HIGH-DEMAND TITLES AND THE PROBLEM WITH BORROWING}

ILL works well for titles that are old and in low demand. When users begin requesting titles that are new or in high demand, the ILL operation becomes problematic. For example, Jane fills out an ILL request for a newly published monograph by a scientist in her field. Instead she receives a cancellation notice: "We're sorry, but this title is too new to borrow from another library." Another user, Carl, needs a copy of a business title that was published in 2007. He thinks he can get it at his local library easily since it is a few years old, but it turns out it is still so popular that the library's copy has a long holds ${ }^{1}$ queue of other users waiting for them. He explains to the circulation librarian that he needs the item immediately and cannot wait for holds, so the librarian suggests going through ILL. After putting in an ILL request, Carl soon receives a cancellation notice not unlike Jane's, saying that the title was unattainable from other libraries-all of their local copies are checked out, too (and therefore unavailable to be loaned to another library). In these cases, daily occurrences in many libraries, neither ILL nor the local library holds process can fill the need of the patron. These new and high-demand (HD) titles make both the holds process (which potentially causes long waits) and the ILL process (which sometimes cannot get an item from another library because their copies are all out) to be less than viable.

When an ILL request is cancelled for these HD titles, users have few alternatives. If they are willing to wait for a few weeks, there are three main options for users. First, if the item is temporarily unavailable (e.g., checked out, missing, or on loan to another library) the user can put the item on hold. The issue there is that the item may have multiple holds, forcing the user to wait her turn. Sometimes the wait is just a few days; sometimes it can take months. In the case of missing books, the patron may never receive the book. This uncertainty can be frustrating, and, when the item is needed by a certain date, this method can be futile since the user may not get the book until past the deadline of its utility. Second, a user could try to find the needed title through another library, either another local library or a partner library that allows reciprocal circulation privileges, such as can be found in a library consortium. Here again, since the item in question has a high level of usage, the other library quite possibly has the same demand as the user's primary library. It is likely that a drive across town to the other library will be 
just as fruitless as contacting one's own library. Third, the patron could ask a friend or relative to lend a copy to them. In these private resource-sharing exchanges the owner of the title usually has their own personal "holds" queue in which the neighbor gets the title next, then a school friend, then a little brother. The wait for the title may actually be longer than going through the primary library holds process. It is important to note that in these cases, the user probably will get the item, but it can take weeks or even months before they do.

If the patron needs the item by a certain date, there are traditionally only two options. First, if the item is not owned by the user's library, or if the holds queue is too long, the user can usually purchase a personal copy. Most HD items are relatively easy to buy through an online vendor or a local bookstore. However, the user presumably came to the library to avoid this option, so this may not be a viable solution. Second, the patron could try ILL again by submitting a second request, assuming the librarian will permit repeat requests. The library is no more likely to get the book this second time around than it was for the first unsuccessful attempt.

\section{PURCHASE INSTEAD OF BORROW}

There is one other option to acquire these HD titles, but it is not initiated by the user, typically, but by the librarian: demand-driven acquisition (DDA). Over the past decade, ILL research has had a burst of articles advocating purchasing instead of borrowing ILL requested books (Tyler, 2011; Way, 2009). Why borrow once what you could purchase and keep for a similar price? Depending on the item and the amount of future use, it can be more cost-effective to buy than to borrow. Perdue and Van Fleet (1999) showed that $96.3 \%$ of all titles purchased instead of borrowed circulated at least once within a four-year period (p. 25). Over that same period only $61 \%$ of firm orders circulated at least once (p. 25). While this number is somewhat suspect since it appears that the initial circulation (where the first user was the ILL requestor who wanted the item) was counted, the study provides a more compelling statistic later: The average number of circulations generally for ILL DDA items was 4.5 uses (3.5 if the initial ILL request circulation is not included) over four years, while the firm order average was only 2.4 (p. 24). In effect, the cost per use of the ILL DDA items was almost half the cost per use of a firm order title.

Although libraries need to consider the full costs of buying instead of borrowing, ${ }^{2}$ ILL DDA programs provide two major benefits to the user. First, purchasing items can fill requests that otherwise would be cancelled. Patrons like Jane and Carl would actually get the item they requested rather than a cancellation notice. Second, every book added to the collection has the potential to fill the requests of future local users. This is an even stronger 
argument, knowing that ILL DDA titles circulate more than titles purchased through traditional acquisitions models (Schroeder, 2012; Tyler, Melvin, Xu, Epp, \& Kreps, 2011). Instead of potentially requesting the same item through ILL multiple times, the library's newly purchased copy can support local need for the life of the book.

Not only can the purchase of ILL requested items help patrons and library budgets, but library holds queues can also help. Holds queue history can illustrate the needs of users over time. The holds queue history is also a useful gauge of the intensity of local interest in a given subject to the title level. How often is a title on hold? On average, how many users are in the queue? Is the demand for a particular title growing or decreasing? Given these metrics, the holds queue history can justify purchasing multiple copies of the same title. This is a drastic departure from conventional collection development and ILL in academic libraries. Rather than direct users to one copy that is perpetually on hold from one user to the next, the purchase of a few more copies, based on demand, can help support user needs better. This reduces costs associated with repeated ILL requests that come when a user sees a local item is checked out. ILL and holds instead can be examined in tandem to determine the best option for the current patron (the one who initiated the ILL request or hold), as well as future patrons who have similar research needs. This article will discuss some possibilities and advantages to using both ILL requests and local holds queues as a way to support patron research needs and to save money over time.

\section{LITERATURE REVIEW}

There are very few studies that examine the impact that holds can have on ILL or vice versa. Much ILL literature focuses on timeliness. One such study by Gregory and Pedersen (2003) examines ILL turnaround time with holds queue turnaround time, illustrating how ILL may be a faster alternative to local holds in certain cases. Gregory and Pedersen found that the turnaround time for a book with only one user in the holds queue (i.e., the next user to obtain the book) is typically faster than an ILL request; once the queue is increased, however, an ILL request may get the book faster. Gregory and Pedersen recommend considering all requests for a book after the first hold be referred to ILL (p. 296). Gregory and Pedersen conclude that "ILL might be an effective, supplementary means of increasing book availability, particularly the availability of [...] books that seldom, if ever, can be found on the shelf but, instead, exist in a perpetual state of transit from reserve operations to [holds] queues to ILL lending and back" (p. 297). Gregory and Pedersen focus their discussion and argue primarily for ILL to support the need of "the timeliness of availability," but by their own admission, these books are difficult to find on the shelf in order to loan to another library 
(p. 297). This dependence on ILL is awkward, since presumably the local holdings of the lending library are in a similarly "perpetual state of transit." A borrowing library's ability to fill these requests would be erratic at best; in the end, instead of potentially getting the book faster than a recall, the user might just get an ILL cancellation notice: "We are sorry. No library could provide this."

Another popular topic in ILL literature, especially recently, focuses on the impact of ILL DDA models and collection development. Statistics that include holds are rarely included in these studies, however, with a few notable exceptions. Ochola (2002) conducted a study on the circulation statistics of monographs within specific collections and compared them to ILL requests for items with a corresponding LC classification. While the findings have been widely shared and commended, Ochola defines circulation as "as a documented process showing that an item has been checked-out by a library patron" (p. 3). Therefore, holds were not taken into account, only the number of times that an item was checked out. Considering the relatively large number of holds that are never picked up, the choice of checkouts over holds seems a more accurate number to work with. Knievel, Wicht, and Connaway (2006) examined their local holdings by discipline and compared their circulation with the number of ILLs for those same disciplines. The results helped their librarians decide which titles stayed in their building and which were sent to a remote storage facility. Schroeder (2012) reviewed the cost per use of DDA titles as compared with traditional acquisitions methods such as firm orders and approval plans. She found that titles purchased to fill an ILL request or to support long holds queues saw much larger circulation than their traditional acquisitions counterparts. A more recent study showed the impact on the combined collection development budgets of a consortium of using holds to manage requests for books at other institutions (Ferguson, Flinchbaugh, \& Moskal, 2013). While there is some discussion on how the holdings of other consortial partners impacted their decision to purchase a title or not, there was no mention of how the consortium handled heavily requested items or if multiple copies of the same title were ever purchased by the same institution. Holds provide an extra metric showing the peaks and valleys of the need for the item over time. It could also support the acquisition of multiple copies of the same item if the item is consistently on hold for multiple users.

Most recently, Waller (2013) compared the cost of borrowing with the cost of purchasing a copy. Waller found that the overhead costs of cataloging, acquisitions, and supplies for his institution was $\$ 11.35$ per book, almost twice what he found was the cost to borrow the same title, $\$ 6.18$ (Table 1). Only $\$ 1.47$ of this cost was for cataloging, the remainder was for supplies or acquisitions and circulation staff processing. This is less than a tenth of the cataloging costs Iowa State University reported in 1997 (Morris, Hobert, Osmus, \& Wool, 2000, p. 74). In that study, Morris et. al. (2000) found that 
TABLE 1 Overhead Costs of Borrowing and Buying

Cost to borrow

Cost to add a new title

Cost to add a new copy
$\$ 6.18$ or $\$ 9.62$

$\$ 11.35+$ cost of the book

$\$ 10.04+$ cost of the book

the cost to recatalog a book represents only $11 \%$ of the $\$ 16.25$ (p. 73). Morris et. al. define recataloging as changes to the catalog record, adding additional copies and volumes to a record, item record creation and bar coding, verification of call numbers, and passing records into the local system (p. 83). Even if the cost to add a copy to an existing record included all of the costs of recatalaoging (which it does not-adding copies to a record does not necessitate changes to the bibliographic record itself, for example, only attaching additional item records), this would only represent a cost of $\$ 1.79$ per copy added, using their 1997 figure or $\$ 0.16$ using Waller's more recent findings. Added to Waller's costs of acquisitions, this would be an adjusted cost to add a DDA copy to $\$ 10.04$, still almost twice the cost to borrow, according to Waller. Leon and Kress (2012) conducted a survey across several midsized academic libraries and found their average mediated borrowing loan was $\$ 9.62$, much higher than Waller's assessment. In either case, we see that ILL is still over 50\% cheaper than purchasing additional copies, but only if an additional copy never is checked out again, after the initial ILL-initiated use.

In the ILL DDA literature there is also a lack of studies that use ILL as an indicator to purchase more than one copy of a title. Most DDA projects advocate purchasing only when the library does not own the title. Few, if any, show the benefits and liabilities of purchasing additional copies based on ILL requests and holds queue size. The current study hopes to fill that lacuna.

\section{ILL AND HOLDS: A NEW PARTNERSHIP}

Instead of relying on ILL to fill requests for items that libraries own but are checked out, libraries should consider the potential impact on user satisfaction and collection development if librarians purchased more local copies based on long holds queues and ILL. Gregory and Pedersen (2003) demonstrate that ILL is faster when holds queues are long. They recommend that a second hold in the holds queue should generate an automatic ILL request since it is likely that that patron would get the book faster than waiting until they are the top hold in the queue (p. 296). However, if an ILL request is generated for the second request and after, the cost in overhead, fees, and maintenance would be $\$ 6.18$ or $\$ 9.62$. This figure only 
accounts for the cost to borrow at the point of a second hold. Libraries should also consider the impact on staff workload. At Brigham Young University's (BYU) Harold B. Lee Library (HBLL), we have an automated holds module through our Integrated Library System (ILS). Our patrons place 3,300 holds per month. This would significantly impact ILL if all second holds generated an ILL request. In the specific case of these HD publications, instead of borrowing automatically, libraries should consider purchasing more copies automatically.

Each library would have to consider their collection development policies (CPD) and also the effect purchasing to support holds and ILL would have. In a 2005 survey, 69\% of libraries surveyed had a section in their CDPs addressing multiple copy purchasing, although this was specifically related to reserve items for curriculum support (Johnson, 2005). Any library considering adding a DDA model for additional copies must consider the following questions: Is the title in question needed primarily for research or recreation? Does that matter? Should the policy be different for nonfiction than for fiction? How many holds per copy are necessary for a librarian to consider purchasing additional copies? How many copies of a title would be the maximum a library would be willing to have?

At BYU, librarians have decided that these HD titles, while perhaps not always used for academic purposes, are still valuable to the overall strength of the collection. We have designated our non-HD titles that are almost exclusively from university presses and other "scholarly" titles as eligible for a second copy once the threshold of two holds per copy is reached. For these HD titles, both fiction and nonfiction, we have made the threshold four holds per copy, realizing that most of these titles are consumed at a faster rate than the non-HD ones and therefore are returned to the library sooner on average than non-HD titles. We generally do not purchase more than seven or eight copies of any title, regardless of popularity.

\section{THE BYU STUDY}

Beginning in late 2006, the HBLL began to purchase additional copies of titles held in the library that had long holds queues. We recently began examining the request history of these types of titles for both ILL and holds queues. This partnership consisted of the ILL Manager, the ILL Borrowing Supervisor, the Circulation Manager, and the Holds Supervisor. We reviewed our holds history between January $2007^{3}$ through December 2009 and identified our titles that had a high-enough threshold of holds in the queue to initiate the purchase of additional copies. We then looked at the number of times our ILL office filled a request for the same titles during the same period of time. 
TABLE 2 MARC Holdings Deflection

\begin{tabular}{ll}
\hline \\
008 8312254p\#\#\#6\#\#\#3\#\#baeng0831017 \\
\hline Will Lend & \\
Will Not Lend & a \\
\hline
\end{tabular}

\section{FINDINGS}

BYU purchased 129 additional copies for 70 titles from 2007 to 2009. Using our earlier figure for the total cost to add a copy to a library collection ( $\$ 10.04)$, the average cost per use (CPU) of each copy across these titles was $\$ 2.00$. Copies that had been purchased in 2007 had an average CPU of $\$ 1.00$. Copies purchased in 2008 had an average CPU of $\$ 1.93$. Copies purchased in 2009 had an average CPU of $\$ 5.47$. As time passes, each copy circulates more, thereby driving down the CPU. As for ILL, the average request filled for these items was $\$ 6.18$ or $\$ 9.62$, the base cost for any mediated borrowing loan request as was stated earlier (Leon and Kress, 2012; Waller, 2013). Taking processing costs into account, the total cost to purchase all 129 additional copies was $\$ 3,177.26$, and the total cost to ILL was $\$ 1,847.82$ or $\$ 2,876.38$. This may seem to show that ILL is more cost-effective than buying and adding the book to the collection. However, when looking at CPU, it becomes clear that over time it is significantly less expensive to buy. For a little less than twice the up-front costs to borrow, we could have ultimately more use out of our local holdings. Moreover, BYU received 529 ILL requests for these titles from 2007 to 2009, but the ILL unit was only able to fill 299 of those requests, a $56.5 \%$ average fill rate. Almost half of our ILL patrons requesting these titles did not get their book. The title Outliers had 11 ILL requests and was filled only two times, a $18.2 \%$ fill rate. In many of these HD cases our patrons do not get the item through a traditional ILL request. Holds, however, has the potential to fill the patron's request $100 \%$ of the time.

\section{CONCLUSION}

Based on these findings, we modified our policy to purchase titles sooner regardless of content. As noted earlier, we purchase now when the queue reaches four holds for all of these HD titles. We resort to ILL only in cases where the need is immediate, the title is not new or popular, and checked out items will not be due back to the library within one week. We identified one week as the cutoff because that tends to be how long it takes to get a book through ILL. If we can get a title just as fast as ILL, since it is due 
to return within a week, we choose not to borrow. For items that will be problematic to get-especially popular items-it is better to send the user back to holds with the understanding that the more users in the queue, the more likely the library will purchase additional copies to support need. It is important also to note that ILL and holds will need to be aware of user demand. ILL and holds personnel should meet often to discuss what titles are popular. The ILL borrowing team will need to keep up with these titles to know that they should not try to borrow in most cases. Similarly, there will occasionally be those users who place a hold and an ILL request on the same title to see who gets the book to them fastest. In these cases of course ILL will "fill" the request through holds.

As we began this program, we quickly discovered an unexpected difficulty: We were lending these HD titles out to other libraries. While we were trying not to borrow these titles, when one of our local copies made its way back to our shelves our lending team would send it out to another university. Not only does this mean our copy could be gone for weeks if not months, it also made the title itself unavailable for holds so local patrons could not tell us they wanted it when it returned. ${ }^{4}$ We brainstormed several different options to address this service defect and found the best one that fit our needs was a cataloging solution. In consultation with OCLC, we attached a MARC holdings record to our monograph bibliographic records. While this is somewhat unorthodox-the MARC holdings record is traditionally used only for serials - it is extremely effective. In the 20th character (on a 0-20 scale) of the 008 Control Field of a MARC holdings record ${ }^{5}$ a library can designate a title as Will Not Lend, by changing the character from an "a" (Will Lend) to a "b" (Will Not Lend), thereby deflecting all requests for these titles, keeping them in the local library (see Table 2). OCLC will return an Auto-deflection message to a potential borrowing library that that title is not available to lend (van Dyk \& Howland, 2011). Other monograph records are not affected and are still eligible for lending. Once again, however, these titles must be reviewed frequently. Eventually HD titles will drop in demand and may be eligible to lend to another institution in time. There must be a mechanism in place to change them back to Will Lend.

One topic that bears further scrutiny is the impact of electronic books in these cases. With the growth of e-book collections for popular literature like Overdrive, are users comfortable enough now to use e-books, or do they still prefer print for popular or new titles? Is it worth purchasing a license for these books and eliminating all print holdings? Some titles may be available only through e-book packages and not available for individual licensing. If both print and e-books are desirable, which users are relegated to the holds queue and which are offered the e-book URL in substitution for an ILL request? How will electronic holds on e-books through services like Overdrive impact this discussion? As we wrestle with these issues in the 
coming years, fortunately we have a viable solution now for print books and whether we should borrow or buy additional copies.

\section{NOTES}

1. For the purposes of this article, holds describes the process in which a user designates an item for use as soon as it becomes available again for checkout, ideally generating a notice from the library saying the item is now available for pick up. In some libraries, this process is called "recalls," while in others recalls are only those items that for whatever reason, must be returned immediately to the library, despite the fact that a user might have several days or weeks before the original due date.

2. See van Dyk, G. (2011).

3. We began in this year because it was the first full year where we had automatically purchased additional copies based on holds queue activity.

4. Our ILS does not allow patrons to place holds on titles that are checked out to our interlibrary loan lending team.

5. See http://www.loc.gov/marc/holdings/hd008.html

\section{REFERENCES}

Ferguson, J., Flinchbaugh, M., \& Moskal, R. (2013). Consortial circulation via patron placed holds in the USMAI's shared catalog and its impact on collection development and ILL. Against the Grain, 16(2), 34, 36, 38.

Gregory, D. J., \& Pedersen, W. (2003). Book availability revisited: Turnaround time for recalls versus interlibrary loans. College \& Research Libraries, 64(4), 283-299.

Johnson, G. J. (2005). By any means necessary: A future for multiple copy provision? SCONUL Focus, 34, 21-26.

Knievel, J. E., Wicht, H., \& Connaway, L. S. (2006). Use of circulation statistics and interlibrary loan data in collection management. College \& Research Libraries, 67(1), 35-49.

Leon, L., \& Kress, N. (2012). Looking at resource sharing costs. Interlending $\mathcal{E}$ Document Supply, 40(2), 81-87.

Morris, D. E., Hobert, C. B., Osmus, L., \& Wool, G. (2000). Cataloging staff costs revisited. Library Resources \& Technical Services, 44(2), 70-83.

Ochola, J. (2002). Use of circulation statistics and interlibrary loan data in collection management. Collection Management, 27(1), 1-12.

Perdue, J., \& Van Fleet, J. A. (1999). Borrow or buy? Cost-effective delivery of monographs. Journal of Interlibrary Loan, Document Delivery \& Information Supply, 9(4), 19-28.

Schroeder, R. (2012). When patrons call the shots: Patron-driven acquisition at Brigham Young University. Collection Building, 31(1), 11-14.

Tyler, D., Melvin, J. C., Xu, Y., Epp, M., \& Kreps, A. M. (2011). Effective selectors? Interlibrary loan patrons as monograph purchasers: A comparative examination of price and circulation-related performance. Journal of Interlibrary Loan, Document Delivery \& Electronic Reserve, 21(1/2), 57-90.

Tyler, D. C. (2011). Patron-driven purchase on demand programs for printed books and similar materials: A chronological review and summary of 
findings. Library Philosophy \& Practice, Paper 635, 108-127. Retrieved from http://digitalcommons.unl.edu/libphilprac/635

van Dyk, G. (2011). Interlibrary loan purchase-on-demand: A misleading literature. Library Collections, Acquisitions, \& Technical Services, 35(2/3), 83-89.

van Dyk, G., \& Howland, J. L. (2011). Of lending and licensing [PowerPoint Slides]. Retrieved from http://www.jaredhowland.com/presentations/lendinglicensing/

Waller, J. H. (2013). Undergrads as selectors: Assessing patron-driven acquisition at a liberal arts college. Journal of Interlibrary Loan, Document Delivery $\&$ Electronic Reserve, 23(3), 127-148.

Way, D. (2009). The assessment of patron-initiated collection development via interlibrary loan at a comprehensive university. Journal of Interlibrary Loan, Document Delivery \& Electronic Reserve, 19(4), 299-308. 